\title{
FAKTOR YANG HUBUNGAN DENGAN PENGETAHUAN POLA MAKAN DAN AKTIVITAS FISIK DENGAN KESTABILAN GULA DARAH PADA PENDERITA DIABETESMELITUS DI PUSKESMAS BINAMU KOTA KAB. JENEPONTO
}

\author{
Syaifuddin Zaenal'1, Hardiyanti Ahmad², St. Saedah³ \\ 1STIKES Nani Hasanuddin Makassar \\ 2STIKES Nani Hasanuddin Makassar \\ 3STIKES Nani Hasanuddin Makassar
}

(Alamat Korespondensi: hardiyantiahmad60@gmail.com / 085248087720)

\begin{abstract}
ABSTRAK
Pengetahuan adalah suatu proses mengingat dan mengenal kembali objek yang telah dipelajari melalui panca indra pada suatu bidang tertentu secara baik. Pola makan yang keliru dan sembarangan menjadi salah satu faktor yang memicu munculnya penyakit diabetes melitus. Diantaranya mengkomsumsi makanan yang terlalu banyak mengandung glukosa atau gula. Aktivitas fisik berdampak terhadap aksi insulin pada orang yang berisiko DM. Penelitian ini bertujuan untuk mengetahui hubungan pengetahuan, pola makan, aktivitas fisik dengan kestabilan gula darah pada penderita diabetes melitus pada penderita diabetes mellitus di puskesmas Binamu Kota kab.Jeneponto Penelitian ini bersifat survey analitik dengan menggunakan pendekatan Cross Sectional study menggunakan desain uji Chi-Square dengan interval kemaknaan $\alpha=0,05$ sampel sebanyak 35 orang yang di dapatkan dengan menggunakan teknik total sampling. Hasil penelitian diperoleh hubungan pengetahuan $(\rho=0,036)$, pola makan $(\rho=0,045)$, dan aktivitas fisik $(\rho=0,035)$ terhadap kestabilan gula darah penderita diabetes melitus. Menunjukkan hungan yang signifikan antara pengetahuan, pola makan, aktivitas fisik dengan kestabilan gula dara pada penderita diabetes melitus di Puskesmas Binamu Kota Kab. Jeneponto.
\end{abstract}

Kata Kunci : Pengetahuan, Pola Makan, Aktivitas Fisik.

\section{PENDAHULUAN}

Diabetes mellitus (DM) adalah suatu sindrom gangguan metabolisme yangditandai dengan hiperglikemia sebagai akibat defesinsi sekresi insulin atau keduanya (Smeltze \& Bere, 2007; Asosiasi diabetes Amerika/American Diabetes Assocition (ADA,2005). Defesiensi fungsi dan sekresi insulin diawali dengan terjadinya prediabetes yang merupakan prakondisi Diabetes.Insulin adalah salah satu hormon yang di hasilkan oleh pankreas dan memegang peran penting dalam menjaga kesimbangan glukosa darah (Rumahorbo, 2014).

Dari data WHO, Indonesia menempati urutan ke-4 terbesar dalam jumlah penderitanya diabetes mellitus di dunia. Di tahun 2000 yang lalu saja, terdapat sekitar 5,6 juta penduduk di Indon ccccesia yang mengidap diabetes. Di tahun 2006 meningkatnya tajam menjadi 14 juta orang, dimana baru 50 persen yang sadar mengidapnya. Dan diantara mereka hanya sekitar 30 persen yang dating berobat teratur, sangat di sayangkan bahwa banyak penderitaa diabetes yang tidak menyadari dirinya mengidap penyakit yang bisa sangat berbahaya (Soedarsono, 2016).

Menurut Depertemen Kesehatan RI (2008),Di Indonesia berdasarkan survai kesehatan rumah tangga (SKRT) tahun 2005 menunjukkan peningkatan prevelensi Diabetes mellitus dari tahun 2001 sebesar 7,5\% menjadi $10,4 \%$ pada tahun 2004 . Sementara itu hasil survai biro pusat statistik (BPS) tahun 2003 menyatakan prevelensi diabetes mellitus diperkotaan mencapai $14,7 \%$ dan $7,2 \%$ di pedesaan. Hasil riset Kesehatan Dasar (Riskesda) tahun 2007 menunjukkan prevelensi diabetes mellitus secara nasional mencapai 5,7\%; prevelensi toleransi glukosa terganggu (TGT) mencapai 10,2\%; prevelensi obesitas umum mencapai $10,3 \%$ dan obisitas sentral mencapai $18.8 \%$. prevelensi Diabetes Melitus di jawa barat mencapai 4,2\% (Rumahorbo, 2014).

Riset Kesehatan Dasar Nasional (Riskesdas) tahun 2013, melaporkan bahwa kasus kencing manis (berdasarkan diagnosis atau gejala klinis) di Indonesia sebesar 2,1\% setelah diadakan pemeriksaan darah dilaboratorium terdapat penduduk yang terkena sampel biomedis, ternyata kasus tersebut jauh lebih besar, yaitu 6.9\% (sama 
dengan menurut data WHO). Angka ini memberikan informasi kepada kita bahwa dari 100 orang penduduk Indonesia yang berusia 15 tahun ke atas, sebanyak 7 orang telah menderita diabetes mellitus (Marewa, 2015).

Tingginya kasus diabetes mellitus tersebut menempatkan Indonesia pada urutan ke-4 terbesar didunia, yang mempunyai penduduk menderita kencing manis setelah india $(79.400,000$ jika tahun 2030), Cina $(42,300,000$ jika pada tahun 2030) dan amerika $(30,300,000$ jika pada tahun 2030) (Marewa, 2015).

Kasus diabetes mellitus di provinsi Sulawesi Selatan yang disebut sebagai prevalens diabetes mellitus, berkisar antara $1,0 \%$ sampai $6,1 \%$ yang terbesar di 25 kabupaten/kota. Kasus diabetes mellitus paling banyak di temukan kabupaten atau kota tanah toraja $(6,1 \%)$, Makassar $(5,3 \%)$, luwu $(5,2 \%)$. Kasus terendah adalah di pangkajene kepulauan, enrekang, dan luwu timur, masingmasing 1\% (Marewa, 2015).

Besarnya kasus diabetes mellitus di Indonesia adalah 2,1\%. Dengan demikian terdapat 5 kabupaten/kota yang berada di bawah prevalensi nasional, yaitu pangkep $(1,0 \%)$, enrekang $(1,0 \%)$, luwu timur $(1,0 \%)$, soppeng $(1,9 \%)$, dan sinjai $(1,9 \%)$. Jika di bandikan dengan kasus di sul-sel (3.4\%), maka terdapat 20 kabupaten/kota yang mempunyai jumlah kasus dibawah provensi (Marewa, 2015).

Pada kasus diabetes mellitus masyarakat sul-sel paling banyak di temukan pada kelompok usia 55-74(13.4\%). Penyakit ini sudah mulai di temukan pada usia 15-24 $(2 \%)$, lebih banyak pada perempuan $(3,6 \%)$, banyak terjadi pada pada pendidikan tamatan D1-D3/PT (3,7\%), bekerja sebagai wiraswasta $(4,5 \%)$, dan terbanyak di perkotaan $(2,4 \%)$ (Marewa, 2015).

Hasil studi pengambilan data awal adalah pada tahun 2017 pasien diabetes mellitus yang melakukan pemeriksaan kesehatan sebanyak 315 orang.Sedangkan pada bulan januari 40 orang sedangkan di bulan februari 24 orang di tahun2018 data pasien diabetes yang telah melakukan pemeriksaan kesehatan sebanyak 64 orang.

Berdasarkan uraian pada latar belakang di atas maka, dapat di rumuskan bahwa "Apakah ada Pengaruh Pengetahuan dan Norma Sosial Terhadap Perilaku Keluarga Dalam Mencegah Penularan Tuberkulosis di Puskesmas Bara-Baraya?"

\section{BAHAN DAN METODE}

Lokasi, Populasi dan Sampel penelitian

Penelitian ini telah dilakukan di puskesmas bianamu kota Jeneponto pada tanggal 2 juli 2018 s/d 26 juli 2018, Populasi dalam penelitian ini adalah semua pasien yang menderita Diabetes Mellitus yang berjumlah 35 orang di Puskesmas binamu kota kabJeneponto, Sampel dalam penelitian ini berjumlah 35 responden. Adapun kriteria inklusi dan ekslusi dari peneliti adalah sebagai berikut:

1. Kriteria Inklusi
a. Pasien yang bersedia menjadi responden
b. Pasien yang terdiagnosa Diabetes Mellitus.
c. Pasien dalam keadaan sadar, bisa membaca dan menulis.

2. Kriteria ekslusi
a. Pasien yang tidak bersedia menjadi responden
b. Pasien yang berumur $<30-60$ tahun
c. Pasien dalam keadaan tidak sadar, tidak bisa membaca dan menulis.

\section{Cara Pengumpulan Data}

1. Data Primer

Data yang diambil oleh responden dengan menggunakan lembar observasional dan kuesioner, dengan menggunakan skala guttman.

2. Data Sekunder

Data yang diperoleh dari instansi terkait sehubungan dengan penelitian.

\section{Pengolahan data}

1. Editing (menyunting data)

$$
\text { Hasil wawancara yang dikumpulkan }
$$
melalui kuesioner disunting terlebih dahulu.

2. Coding (membuat lembaran kode) Lembaran code adalah instrument yang berupa kolom-kolom untuk merekam data secara manual.

3. Processing (memasukkan data)

Jawaban dari masing-masing responden yang dalam bentuk kode dimasukkan kedalam program SPSS 22 for window dengan uji statistic Chi-Square .

4. Cleansing ( pembersihan data)

Apabila semua data dari setiap sumber data atau responden selesai dimasukkan, perlu dicek kembali untuk melihat kemungkinan adanya kesalahan kode, kemudian dilakukan pembetulan.

\section{Analisis data}

1. Analisis Univariat

Analisis univariat dilakukan pada tiap variabel dari hasil penelitian dengan mendeskripsikan setiap variabel penelitian dengan cara membuat tabel distribusi frekuensi pada tiap variabel. 
2. Analisis Bivariabel

Analisis bivariat yaitu untuk melihat hubungan antara variabel independen dengan variabel dependen.

\section{HASIL PENELITIAN}

1. Analsis Univariat

Tabel 1 Distribusi Frekuensi Karakteristik Responden Penderita Diabetes Melitus di Puskesmas Binamu Kab.Jeneponto

\begin{tabular}{|c|c|c|}
\hline Karakteristik & $(\mathrm{n})$ & $(\%)$ \\
\hline Umur & 17 & 48,6 \\
$30-50$ & 18 & 51,4 \\
$>50$ & 35 & $100 \%$ \\
\hline Total & & \\
\hline
\end{tabular}

Dari tabel diatas maka diketahui bahwa pengetahuan responden kategori cukup sebanyak 6 orang (34,3\%), sedagkan pengetahuan reponden kategori kurang sebanyak 29 orang $(65,7 \%)$.

2. Analisis Bivariat

Tabel 2 Pengaruh Pengetahuan Terhadap Perilaku Keluarga di Wilayah Kerja Puskesmas Bara-Baraya Kota Makassar

\begin{tabular}{|c|c|c|c|c|c|c|}
\hline \multirow{2}{*}{ Pengetahuan } & \multicolumn{3}{|c|}{ Kestabilan gula darah } & \multicolumn{2}{c|}{ Total } \\
\cline { 2 - 6 } & \multicolumn{2}{|c|}{ Normal } & $\begin{array}{c}\text { Tidak } \\
\text { normal }\end{array}$ & \multicolumn{2}{c|}{} \\
\cline { 2 - 7 } & $\mathrm{n}$ & $\%$ & $\mathrm{n}$ & $\%$ & $\mathrm{n}$ & $\%$ \\
\hline Normal & 10 & 28,6 & 13 & 37,1 & 23 & 65,7 \\
\hline Tidak normal & 1 & 2,9 & 11 & 31,4 & 11 & 31,4 \\
\hline Total & 11 & 31,4 & 24 & 68,6 & 24 & 68,6 \\
\hline \multicolumn{7}{|c|}{$p=0,036$} \\
\hline
\end{tabular}

Berdasarkan tabel diatas menunjukkan bahwa dari 35 orang responden $(65,5 \%)$ pada pengetahuan di kategorikan baik di dapatkan 10 orang responden (28,6\%) pada pengetahuan kategori kurang 1 orang responden (2,9\%). Dengan gula darah normal dan 13 orang lainnya $(37,1 \%)$ dengan guala darah tidak normal sedangkan dari total 10 responden $(28,6 \%)$ pada pengetahuan kurang, didapatkan 1 orang responden (2,9\%) dengan gula darah yang normal dan ada 24 orang lainnya dengan gula darah tidak normal.

Setelah dilukan analisis uji statistik menggunakan chi square, maka berdasarkan nilai Fisher's Exate test di dapatkan nilai $p=0,35$ dimana $p<a \quad 0,05$, maka dengan demikian dapat di simpulkan bahwa ada hubungan yang signifikan antara pengetahuan dengan kestabilan gula darah penderita diabetes mellitus di Puskesmas Binamu Kota Kab. Jeneponto.

Tabel 3 Hubungan Pola Makan terhadap Pesien Diabetes Mellitus Di Puskesmas Binamu Kota Kab.Jeneponto

\begin{tabular}{|c|c|c|c|c|c|c|}
\hline \multirow{2}{*}{$\begin{array}{c}\text { Pola } \\
\text { Makan }\end{array}$} & \multicolumn{2}{|c|}{ Kestabilan Gula Darah } & \multicolumn{2}{|c|}{ Total } \\
\cline { 2 - 6 } & $\mathrm{n}$ & $\%$ & $\mathrm{n}$ & $\%$ & $\mathrm{n}$ & $\%$ \\
\hline Baik & 6 & 17,1 & 21 & 60,0 & 27 & 77,1 \\
\hline $\begin{array}{c}\text { Kurang } \\
\text { Baik }\end{array}$ & 5 & 14,3 & 3 & 8,6 & 8 & 82,9 \\
\hline Total & 11 & 31,4 & 24 & 68,6 & 35 & 100,0 \\
\hline \multicolumn{7}{|c|}{$p=0,045$} \\
\hline
\end{tabular}

Berdasarkan tabel diatas dapat disimpulkan dari 35 orang responden $(100 \%)$. Responden yang mengalami pola makan baik sebanyak 27 orang $(77,1 \%)$ dan responden yang mengalami pola makan kurang baik sebanyak 8 orang (86,9\%). Dan dari responden yang mengalami pola makan dengan baiknormal sebanyak 6 orang $(17,1 \%)$ dan tidak normal sebanyak 21 orang $(60,0 \%)$. Dan dari responden yang mengalami pola makankurang baik dengan normal sebanyak 5 orang $(14,3 \%)$ dan tidak normal sebanyak 3 orang $(8,6 \%)$.

Setelah dilakukan analisa bivariat dengan mengunakan uji chi-square.Maka berdasarkan Fisher's Exate sedangkan nilai $p=0.045$ dimana $p<a \quad 0,05$ maka dengan demikan dapat disimpulkan bahwa ada hubungan yang signifikan antara pola makan dengan kestabilan gula darah penderita diabetes mellitus di Puskesmas Binamu Kota Kab. Jeneponto.

Tabel 4 Hubungan Pola Makan terhadap Pesien Diabetes Mellitus Di Puskesmas Binamu Kota Kab.Jeneponto

\begin{tabular}{|c|c|c|c|c|c|c|}
\hline \multirow{3}{*}{$\begin{array}{l}\text { Aktivita } \\
\text { s Fisik }\end{array}$} & \multicolumn{4}{|c|}{$\begin{array}{c}\text { Kestabilan Gula } \\
\text { Darah }\end{array}$} & \multirow{2}{*}{\multicolumn{2}{|c|}{ Total }} \\
\hline & \multicolumn{2}{|c|}{ Normal } & \multicolumn{2}{|c|}{$\begin{array}{l}\text { Tidak } \\
\text { Normal }\end{array}$} & & \\
\hline & $\mathrm{n}$ & $\%$ & $n$ & $\%$ & $\mathrm{n}$ & $\%$ \\
\hline Baik & 7 & 20,0 & 6 & 17,1 & 13 & 37,1 \\
\hline Kurang & 4 & 11,4 & 18 & 51,4 & 22 & 62,9 \\
\hline Total & 11 & 31,4 & 24 & 68,6 & 35 & $\overline{100,0}$ \\
\hline
\end{tabular}

Berdasarkan tabel 4 maka diketahui bahwa dari total 13 orang responden $(37,1 \%)$ pada kativitas fisik di kategori baik, didapatkan 7 orang responden $(20,0 \%)$ dengan gula darah 
yang tidak normal 6 orang lainnya $(17,1 \%)$ dengan gula darah yang tidak normal. Sedangkan dari total 24 responden $(68,6 \%)$ pada aktivitas fisik diktakan kurang, didapatkan 4 orang responden (!!,4\%) dengan gula darah normal dan 18 orang lainnya $(51,4 \%)$ dengan gula darah tidak normal.

Setelah di lakukan analisis uji statistic menggunakan chi square, maka berdasarkan nilai Fisher's Exatc Test didapatkan nilai $p=0.035$ dimana $p<a$ 0,05 , maka dengan demikan dapat disimpulkan bahwa ada hubungan yang signifikan antara aktivitas fisik dengan kestabilan gula darah penderita diabetes mellitus di Puskesmas Binamu Kota Kab. Jeneponto

\section{PEMBAHASAN}

1. Hubungan pengetahuan antara kestabilan gula darah pada penderita diabetes mellitus di Puskesmas Binamu Kota Kab. Jeneponto

Berdasarkan hasil penelitian maka di ketahui dari total 35 orang responden $(65,5 \%)$ pada pengetahuan di kategorikan baik di dapatkan 10 orang responden (28,6\%) pada pengetahuan kategori kurang 1 orang responden (2,9\%). Dengan gula darah normal dan 13 orang lainnya $(37,1 \%)$ dengan guala darah tidak normal sedangkan dari total 10 responden $(28,6 \%)$ pada pengetahuan kurang, didapatkan 1 orang responden $(2,9 \%)$ dengan gula darah yang normal dan ada 24 orang lainnya dengan gula darah tidak normal.

Setelah dilukan analisis uji statistik menggunakan chi square, maka berdasarkan nilai Fisher's Exate test di dapatkan nilai $p=0,35$ dimana $p<a 0,05$, maka dengan demikian dapat di simpulkan bahwa ada hubungan yang signifikan antara pengetahuan dengan kestabilan gula darah penderita diabetes mellitus di Puskesmas Binamu Kota Kab. Jeneponto.

Hal ini sejalan dengan Soekanto (2002) dalam (Lestari, 2015) mengatakan pengetahuan merupakan hasil dari tahu. Merupakan domain yang penting dalam membentuk tindakan seseorang (overt behavior). Proses kognitif meliputu ingatan, pikiran, persepsi, symbol-simbol penalaran dan pencegahan personal.

Menurut penelitian sebelumnya meunjukkan bahwa ada hubungan pengetahuan dengan kadar gula dalam darah pada pasien diabetes mellitus nilaisignifikan $\rho$ value sebesar 0,35 ( $\rho$ value $<0,05$ )

Menurut peneliti pengetahuan adalah suatu proses memahami dan mengenal dan mengingat kembali apa yang telah dipelajari pada suatu bidang tertentu secara baik.

2. Hubungan antara pola makan dengan kestabilan gula darah pada penderita diabetes

Berdasarkan tabel 5.6 diatas dapat disimpulkan dari 35 orang responden (100\%). Responden yang mengalami pola makan baik sebanyak 27 orang $(77,1 \%)$ dan responden yang mengalami pola makan kurang baik sebanyak 8 orang (86,9\%). Dan dari responden yang mengalami pola makan dengan baiknormal sebanyak 6 orang $(17,1 \%)$ dan tidak normal sebanyak 21 orang $(60,0 \%)$. Dan dari responden yang mengalami pola makankurang baik dengan normal sebanyak 5 orang $(14,3 \%)$ dan tidak normal sebanyak 3 orang $(8,6 \%)$.

Setelah dilakukan analisa bivariat dengan mengunakan uji chi-square.Maka berdasarkan Fisher's Exate sedangkan nilai $p=0.045$ dimana $p<a \quad 0,05$ maka dengan demikan dapat disimpulkan bahwa ada hubungan yang signifikan antara pola makan dengan kestabilan gula darah penderita diabetes mellitus di Puskesmas Binamu Kota Kab. Jeneponto.

Hal ini sejalan dengan (Soedarsono, 2016), bahwa Penderita penyakit diabetes harus mematuhi saran dari dokter untuk memberikan konsultasi.Mematuhi jadwal makan dari dokter, dan dan paling penting pantang yang manis-manis.

Menurut penelitian yang dilakukan Rahma Amtiria (2015) menunjukan bahwa terdapat hubungan yang signifikan antara pola makan dan kadar gula darah, $\rho$ value sebesar 0,045 ( $p$ value $<0,05)$.

Menurut peneliti penderita diabetes melitus harus dapat mengatur pola makan dengan baik dan benar, mengatur porsi makan dan mengontrol berat badan secara berkala.

3. Hubungan antara aktivitas fisik dengan kestabialan gula darah pada penderita diabetes mellitus

Berdasarkan hasil penelitian maka diketahui bahwa dari total 13 orang responden $(37,1 \%)$ pada kativitas fisik di kategori baik, didapatkan 7 orang responden $(20,0 \%)$ dengan gula darah yang tidak normal 6 orang lainnya $(17,1 \%)$ dengan gula darah yang tidak normal. 
Sedangkan dari total 24 responden $(68,6 \%)$ pada aktivitas fisik diktakan kurang, didapatkan 4 orang responden $(31,4 \%)$ dengan gula darah normal dan 18 orang lainnya $(51,4 \%)$ dengan gula darah tidak normal.

Setelah di lakukan analisis uji statistic menggunakan chi square, maka berdasarkan nilai Fisher's Exatc Test didapatkan nilai $p=0.035$ dimana $p<a$ 0,05 , maka dengan demikan dapat disimpulkan bahwa ada hubungan yang signifikan antara aktivitas fisik dengan kestabilan gula darah penderita diabetes mellitus di Puskesmas Binamu Kota Kab. Jeneponto

Menurut penelitian yang dilakukan (Nurliana, 2014) menunjukan bahwa ada hubungan yang signifikan antara aktifitas fisik dengan kestabilan gula darah pada penderita diabetes melitus di RSUD salewangan maros.

\section{KESIMPULAN}

1. Ada hubungan yang signifikan antara pengetahuan dengan kestabilan gula darah pada penderita diabetes melitus di Puskesmas Binamu Kota Kab. Jeneponto.

2. Ada hubungan yang signifikan antara pola makan dengan kestabilan gula darah pada penderita diabetes melitus di
Puskesmas Binamu Kota Kab. Jeneponto.

3. Ada hubungsn ysng dignifikan antara aktivitas fisik dengan kestabilan gula darah pada penderita diabetes melitus di Puskesmas Binamu Kota Kab. Jeneponto.

\section{SARAN}

1. Disarankan agar pasien lebih memperbanyak lagi pengetahuan tentang cara mengkomsusi makan yang rendah lemak dan karbohidratagar kadar glukosa dalam darah dapat dikontrol dengan baik, disamping berolahraga secara rutin minimal $3 x$ sehari, dan memperbanyak aktivitas di rumah.

2. Disarakan kepeda dokter perawat dan petugas kesehatan lainnya agar lebih baik intensif memberikan informasi tentang pentingnya pengaturan pola makan dan aktivitas fisik kepada pederita diabetes melitusagar komplikasi lebih lanjut dihindari sedini mungkin.

3. Disarankan kepada peneliti selanjutnya agar memliti variabel lain yang dianggap amampu mempengaruhi kestabiln gula darah pasien diabetes melitus guna kemajuan dan memperkembangkan ilmu pengetahuan di masa akan datang lebih baik lagi.

\section{DAFTAR PUSTAKA}

Lestari, T. (2015). Kumpulan Teori Untuk Kajian Pustaka Penelitian kesehatan. Yogyakarta: Nuha Medika.

Marewa, L. W. (2015). Kencing Manis (Diabetes Melitus) Di Sulawesi Selatan (Pertama). Jakarta: Yayasan Pustaka Obor Indonesia.

Nurliana, A. (2014). Hubungan Pengetahuan, Pola Makan Dan Aktivitas Fisik Dengan Kestabilan Gula Darah Penderita Diabetes Mellitus Di Rsud Salewangan Maros. Jurnal IImiah Kesehatan, 4(5). https://doi.org/ISSN : 2302-1721

Rumahorbo, H. (2014). Mencegah Diabetes Melitus Dengan Perubahan Gaya Hidup. Bogor: In Media.

Soedarsono. (2016). Cara Alami Mencegah \& Mengobati Diabetes. (Soedarsono, Ed.) (Pertama). Surabaya: Stomata. 